\title{
Factors associated with early failure of vascular access in acute-phase patients
}

\author{
Akihito Tanaka*, Daijo Inaguma, Yu Watanabe, Eri Ito, Naoki Kamegai, Hiroya Shimogushi, Hibiki Shinjo, \\ Kiyomi Koike, Yasuhiro Otsuka and Asami Takeda
}

\begin{abstract}
Background: Acute-phase patients sometimes require hemodialysis therapy without vascular access (VA) present on admission. These patients require VA creation to continue hemodialysis after discharge. The risk of early VA failure in acute-phase conditions is considered high due to the unstable nature of the patients' condition. Hence, optimal timing of VA creation is not established.
\end{abstract}

Methods: This retrospective study included patients who had VA (arteriovenous fistula or graft) created between May 2010 and July 2016.

Results: During this study, 913 VA creations were performed among 804 patients. Of the included, 435 were acute-phase patients (275 men, 160 women). The average age was $67.4 \pm 14.7$ years. The causes of admission were exacerbation of renal failure (274 patients, $63.0 \%$ ), heart disease (61 patients, $14.0 \%)$, infectious disease (30 patients, $6.9 \%$ ), and malignancy (15 patients, $3.4 \%$ ). Early VA failure occurred in 53 patients (12.2\%). There was no difference in causes of admission between patients with and without VA failure. Serum albumin level was significantly lower $(2.7 \pm 0.8 \mathrm{~g} / \mathrm{dL}$ vs. $3.0 \pm 0.6 \mathrm{~g} / \mathrm{dL}, P<0.01)$ in the early VA failure group than in the without early failure group. Albumin level was associated with early VA failure (odds ratio $0.4723,95 \%$ confidence interval $0.2744-0.8130$, $P<0.01$ ). Assessing only patients with arteriovenous fistula, the serum albumin level was significantly lower $(2.6 \pm 0.7 \mathrm{~g} / \mathrm{dL}$ vs. $3.1 \pm 0.6 \mathrm{~g} / \mathrm{dL}, P<0.01)$ in the early VA failure group than in the without early failure group.

Conclusions: When we perform VA creation in acute-phase patients, hypoalbuminemia is associated with the risk of early VA failure. The status of the patient is an important factor to consider when creating VA.

Keywords: Early failure, Hemodialysis, Vascular access

\section{Background}

Patients, especially those with chronic kidney disease, who are admitted to the hospital with acute-phase illness, such as cardiovascular disease, infectious disease, and stroke, sometimes complicate with acute kidney injury and transition into end-stage renal disease (ESRD), which requires dialysis therapy. Furthermore, ESRD patients sometimes complicate with acute-phase illness and are admitted to the hospital with vascular access (VA) occlusion as a result. As our hospital has an emergency unit, many patients, with various diseases, are referred to our hospital without usable VA. VA must be created to continue hemodialysis (HD). However, the patient state during the acute phase is

\footnotetext{
* Correspondence: zhangren_at_23@yahoo.co.jp

Kidney Disease Center, Japanese Red Cross Nagoya Daini Hospital, 2-9, Myoken-cho, Showa-ku, Nagoya 466-8650, Japan
}

unstable, as evidenced by symptoms such as unstable blood pressure, hypercoagulation, and intravascular volume depletion. Hence, the risk of early VA failure during the acute-phase condition is considered to be increased. Furthermore, patients with complications, such as cardiovascular and cerebrovascular diseases, often already demonstrate advanced atherosclerosis. Hence, the maturation of VA may be poor. Clinically, we decide the timing of VA creation by taking general condition, such as blood pressure, fluid volume, and presence of infection, into consideration. However, there is no established evidence showing what condition is optimal for VA creation. Some studies report that a small-diameter artery or vein is a disadvantage for VA maturation. Low volume of VA flow is also a reported disadvantage. However, regarding patients with VA placed during the acute phase, 
there is no information reported on optimal timing for VA maturation.

We herein assessed the factors of early VA failure in patients with VA placement during the acute phase.

\section{Methods}

\section{Patients and data collection}

This is a retrospective study. We included patients who had VA created between May 2010 and July 2016. Primary cause of admission, past history, physical examination, and laboratory data were collected from medical records. Blood pressure was defined as the reading immediately before VA creation. Laboratory data were defined as the most recent (within 1 week) prior to the first VA creation. Inclusion criteria consisted of the following: adult patient with VA creation performed, VA not available on admission, VA placed during hospitalization, hospitalization length of stay more than 3 days, and VA used at least once in our hospital. Because in our hospital the period of hospitalization for only VA creation is usually within 3 days, longer hospitalization means that there is other reason to continue hospitalization. Acute-phase illness means various ones which require admission other than VA creation. Exclusion criteria included patient death during hospitalization.

\section{Vascular access creation}

According to past reports, VA was created with vascular mapping by ultrasonography. An artery and a vein greater than $1.5 \mathrm{~mm}$ in diameter were used to create arteriovenous fistulas (AVF). If AVF creation was difficult, arteriovenous grafts (AVG) were created. An operating surgeon or instructor had more than 10 years of experience.

\section{Definition of early vascular access failure}

Early VA failure was defined as a case in which VA creation surgery was required two or more times during one hospitalization because first VA did not become usable.

\section{Statistical analysis}

Baseline characteristics were presented descriptively and were tested using Student's $t$ test or $\chi^{2}$ test. Logistic regression analysis and receiver operative characteristic (ROC) curve were used to evaluate early VA failure after acute-phase hospitalization. $P$ values $<0.05$ were considered statistically significant.

\section{Results}

\section{Baseline characteristics}

During the period of this study, 913 VA creations in 804 patients were performed. Of them, 452 patients had VA creations performed during acute-phase condition. Of the 452 patients, 17 died before discharge. The remaining 435 patients (275 men and 160 women) were assessed. The average age was $67.4 \pm 14.7$ years. Table 1 depicts the
Table 1 Baseline characteristics of patients receiving VA placement $(n=435)$

\begin{tabular}{ll}
\hline Parameter & \\
\hline Age (years) & $67.4 \pm 14.7$ \\
Male/female & $275 / 160$ \\
Diabetes (\%) & 46.0 \\
Hypertension (\%) & 67.6 \\
Atrial fibrillation (\%) & 9.2 \\
Primary cause of admission & \\
Exacerbation of renal failure (\%) & 63.0 \\
Heart disease (\%) & 14.0 \\
Heart failure (\%) & 10.6 \\
Coronary artery disease (\%) & 2.3 \\
Infectious disease (\%) & 6.9 \\
Malignancy (\%) & 3.4 \\
Cephalopathy (\%) & 2.8 \\
Cerebral infarction (\%) & 0.7 \\
Intracranial hemorrhage (\%) & 0.9 \\
Peripheral artery disease (\%) & 0.7 \\
Aortic disease (\%) & 0.9 \\
Others (\%) & 8.3 \\
AVF (\%) & 76.1 \\
Early failure (\%) & 12.2 \\
\hline V vascula access, $\%$ F antovenous fistula
\end{tabular}

$V A$ vascular access, AVF arteriovenous fistula

baseline profile of all patients. The most frequent primary cause of admission was exacerbation of renal failure. Early VA failure occurred in $12.2 \%$ of patients.

\section{Characteristics of patients with and without early failure of vascular access}

Table 2 is a comparison of patients with and without early VA failure. There was no significant difference between the patients with and without VA failure in age, past history, primary cause of admission, medication, or cardiac function. However, the percentage of male was significantly lower in the early VA failure group. Further, diastolic blood pressure (DBP) was significantly lower in the early VA failure group than in the without early VA failure group. Serum albumin level (ALB) was significantly lower and Creactive protein (CRP) higher in the early VA failure group.

\section{The impact of serum ALB levels on early VA failure}

Table 2 displays the association between early VA failure and DBP, serum ALB, or CRP. Table 3 shows non-adjusted odds ratios after logistic regression analysis using early VA failure as the objective variable. Table 4 illustrates odds ratio adjusted by age, gender, past history of diabetes, DBP, serum ALB, creatinine (Cr), CRP, and AVF. Only the level of serum ALB showed significant association with early VA failure. 
Table 2 Characteristics of patients with and without early VA failure

\begin{tabular}{|c|c|c|c|}
\hline Parameter & $\begin{array}{l}\text { Without failure } \\
(n=382)\end{array}$ & $\begin{array}{l}\text { With failure } \\
(n=53)\end{array}$ & $P$ value \\
\hline Age (years) & $66.9 \pm 14.6$ & $70.7 \pm 15.6$ & 0.0819 \\
\hline Male (\%) & 65.2 & 49.1 & $0.0225^{*}$ \\
\hline Diabetes (\%) & 45.0 & 52.8 & 0.2854 \\
\hline Hypertension (\%) & 68.3 & 62.3 & 0.3770 \\
\hline Atrial fibrillation (\%) & 8.3 & 15.1 & 0.1128 \\
\hline \multicolumn{4}{|l|}{ Primary cause of admission } \\
\hline Exacerbation of CRF (\%) & 64.1 & 54.7 & 0.1832 \\
\hline Heart disease (\%) & 13.6 & 17.0 & 0.5081 \\
\hline Heart failure (\%) & 9.9 & 15.1 & 0.2535 \\
\hline Coronary artery disease (\%) & 2.4 & 1.9 & 0.8309 \\
\hline Infectious disease (\%) & 6.5 & 9.4 & 0.4366 \\
\hline Malignancy (\%) & 3.4 & 3.8 & 0.8898 \\
\hline Cephalopathy (\%) & 2.6 & 3.8 & 0.6302 \\
\hline Cerebral infarction (\%) & 0.5 & 1.9 & 0.2611 \\
\hline Intracranial hemorrhage (\%) & 1.0 & 0.0 & 0.4542 \\
\hline Peripheral artery disease (\%) & 0.5 & 1.9 & 0.2611 \\
\hline Aortic disease (\%) & 1.0 & 0.0 & 0.4542 \\
\hline Others (\%) & 8.1 & 9.4 & 0.7440 \\
\hline Warfarin (\%) & 9.7 & 11.3 & 0.7086 \\
\hline Antiplatelet agent (\%) & 31.2 & 32.1 & 0.8919 \\
\hline Statin (\%) & 32.2 & 30.2 & 0.7687 \\
\hline ACEi or ARB (\%) & 46.9 & 41.5 & 0.4642 \\
\hline Beta blocker (\%) & 34.0 & 34.0 & 0.9921 \\
\hline CCB (\%) & 60.0 & 60.4 & 0.9523 \\
\hline LVEF (\%) & $55.6 \pm 12.9$ & $56.5 \pm 12.7$ & 0.7022 \\
\hline SBP $(\mathrm{mmHg})$ & $138.6 \pm 24.2$ & $132.1 \pm 23.7$ & 0.0671 \\
\hline DBP (mmHg) & $75.1 \pm 16.2$ & $69.1 \pm 17.3$ & $0.0119^{*}$ \\
\hline WBC $\left(10^{3} / \mu \mathrm{L}\right)$ & $7.2 \pm 3.2$ & $8.0 \pm 3.5$ & 0.0870 \\
\hline $\mathrm{Hb}(\mathrm{g} / \mathrm{dL})$ & $9.8 \pm 1.7$ & $9.7 \pm 1.9$ & 0.6712 \\
\hline $\operatorname{PLT}\left(10^{4} / \mu \mathrm{L}\right)$ & $19.2 \pm 7.8$ & $19.7 \pm 8.3$ & 0.6834 \\
\hline TP (g/dL) & $6.1 \pm 0.9$ & $5.9 \pm 1.0$ & 0.1570 \\
\hline ALB (g/dL) & $3.0 \pm 0.6$ & $2.7 \pm 0.8$ & $0.0002^{* *}$ \\
\hline BUN (mg/dL) & $68.5 \pm 28.7$ & $63.0 \pm 34.2$ & 0.2035 \\
\hline $\mathrm{Cr}(\mathrm{mg} / \mathrm{dL})$ & $7.3 \pm 3.0$ & $6.4 \pm 2.4$ & $0.0414^{*}$ \\
\hline eGFR (mL/min/1.7 m²) & $7.3 \pm 3.9$ & $7.6 \pm 3.6$ & 0.6209 \\
\hline AST (IU/L) & $23.2 \pm 20.0$ & $25.8 \pm 24.9$ & 0.3891 \\
\hline $\mathrm{ALT}(\mathrm{IU} / \mathrm{L})$ & $18.9 \pm 21.3$ & $17.7 \pm 21.4$ & 0.7076 \\
\hline CRP (mg/dL) & $2.2 \pm 3.3$ & $3.2 \pm 4.4$ & $0.0390^{*}$ \\
\hline APTT & $30.2 \pm 9.7$ & $31.2 \pm 8.1$ & 0.5918 \\
\hline PT-INR & $1.16 \pm 0.40$ & $1.16 \pm 0.20$ & 0.9994 \\
\hline $\operatorname{AVF}(\%)$ & 77.5 & 66.0 & 0.0671 \\
\hline
\end{tabular}

$V A$ vascular access, $C R F$ chronic renal failure, $A C E i$ angiotensin-converting enzyme inhibitor, $A R B$ angiotensin receptor blocker, $C C B$ calcium channel blocker, LVEF left ventricular ejection fraction, $S B P$ systolic blood pressure, $D B P$ diastolic blood pressure, $W B C$ white blood cell, $H b$ hemoglobin, PLT platelet, TP total protein, $A L B$ albumin, $B U N$ blood urea nitrogen, $C r$ creatinine, eGFR estimated glomerular filtration rate, AST aspartate aminotransferase, $A L T$ alanine transaminase, CRP Creactive protein, $A P T T$ activated partial thromboplastin time, $P T-I N R$ international normalized ratio of prothrombin time, $A V F$, arteriovenous fistula ${ }^{*} P<0.05 ;{ }^{* *} P<0.01$
Table 3 Odds ratio for early VA failure with evaluated parameters (non-adjusted)

\begin{tabular}{lcll}
\hline Parameter & Odds ratio & $95 \% \mathrm{Cl}$ & $P$ value \\
\hline DBP $(\mathrm{mmHg})$ & 0.9770 & $0.9593-0.9950$ & $0.0124^{*}$ \\
ALB $(\mathrm{g} / \mathrm{dL})$ & 0.4287 & $0.2709-0.6784$ & $0.0003^{* *}$ \\
$\mathrm{Cr}(\mathrm{mg} / \mathrm{dL})$ & 0.8929 & $0.8003-0.9961$ & $0.0424^{*}$ \\
$\mathrm{CRP}(\mathrm{mg} / \mathrm{dL})$ & 1.0728 & $1.0017-1.1489$ & $0.0447^{*}$ \\
AVF & 0.5649 & $0.3048-1.0471$ & 0.0697 \\
\hline
\end{tabular}

$V A$ vascular access, $C l$ confidence interval, $D B P$ diastolic blood pressure, $A L B$ albumin, $C r$ creatinine, $C R P$ C-reactive protein, $A V F$ arteriovenous fistula ${ }^{*} P<0.05 ;{ }^{* *} P<0.01$

\section{Receiver operative curve for early VA failure}

The data in Tables 3 and 4 support the association between early VA failure and serum ALB, so a ROC curve was assessed to detect early VA failure. Figure 1 illustrates the ROC curve of serum ALB. From this finding, we considered serum ALB less than $2.82 \mathrm{~g} / \mathrm{dL}$ to be the cutoff level to predict early VA failure.

\section{Analyses for only AVF}

Next, we assessed only patients with AVF because the characteristics of AVG failure may be different from the ones in AVF. We assessed for majority of our patients with AVF $(n=331)$. Table 5 is a comparison of patient-created AVF with and without early VA failure. There was no significant difference between the patients with and without VA failure in age, past history, primary cause of admission, medication, or cardiac function. However, the level of ALB was significantly lower and white blood cell count higher in the early VA failure group. Table 6 shows non-adjusted and Table 7 shows adjusted odds ratios using early VA failure as the objective variable. Table 7 illustrates odds ratio adjusted by age, gender, past history of diabetes, white blood cell count, and serum ALB. Only the level of serum ALB showed significant association with early VA failure in patients with AVF.

\section{Discussion}

In this study, we evaluated the association between early VA failure and serum ALB level in acute-phase illness

Table 4 Odds ratio for early VA failure with evaluated parameters (adjusted)

\begin{tabular}{llll}
\hline Parameter & Odds ratio & $95 \% \mathrm{Cl}$ & $P$ value \\
\hline DBP $(\mathrm{mmHg})$ & 0.9866 & $0.9668-1.0068$ & 0.1924 \\
ALB $(\mathrm{g} / \mathrm{dL})$ & 0.4723 & $0.2744-0.8130$ & $0.0068^{* *}$ \\
$\mathrm{Cr}(\mathrm{mg} / \mathrm{dL})$ & 1.0270 & $0.8977-1.1748$ & 0.6980 \\
$\mathrm{CRP}(\mathrm{mg} / \mathrm{dL})$ & 1.0444 & $0.9639-1.1316$ & 0.2883 \\
AVF & 0.6260 & $0.3239-1.2097$ & 0.1634 \\
\hline
\end{tabular}

Adjusted by age, gender, diabetes, DBP, ALB, Cr, CRP, and AVF

$V A$ vascular access, $C l$ confidence interval, $D B P$ diastolic blood pressure,

$A L B$ albumin, $\mathrm{Cr}$ creatinine, CRP C-reactive protein, $A V F$ arteriovenous fistula ${ }^{* *} P<0.01$ 


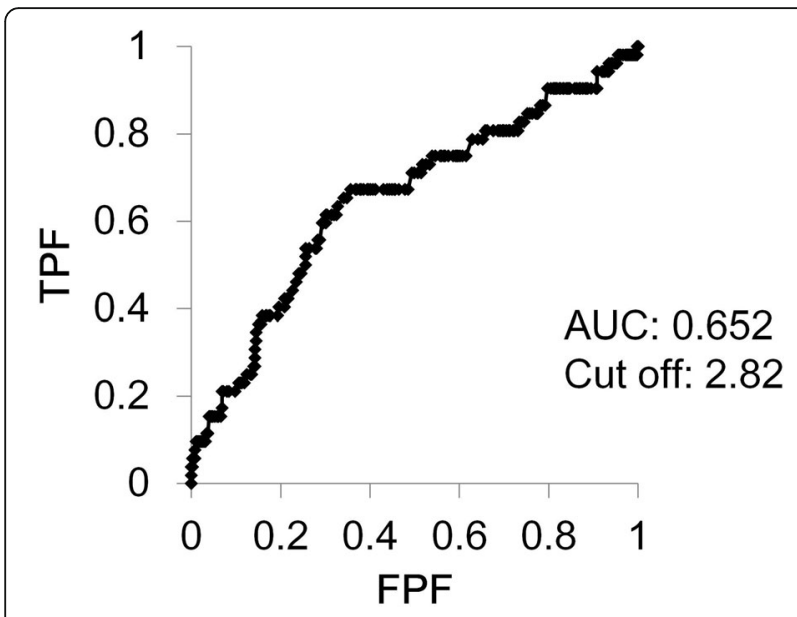

Fig. 1 The ROC curve for early vascular access failure using serum ALB levels in all patients. The AUC of ALB is 0.652 and the cutoff value is $2.82 \mathrm{~g} / \mathrm{dL}$. ROC receiver operative characteristic, $A L B$ albumin, $A U C$ area under the curve, TPF true positive fraction, FPF false positive fraction

patients who were admitted to our hospital and required dialysis therapy. On the other hand, there was no relation between early VA failure and the type of acutephase illness. We opine that the more important point for VA creation is a stable condition, rather than cause of admission or type of medicine. In other words, to decide the timing of VA creation, it is more important to confirm that the patient's condition is stable.

Past reports assessed early VA failure regardless of the presence of acute-phase illness. Despite better patient condition due to the absence of acute-phase illness, 20 to $60 \%$ early VA failure was reported $[1,2]$. The prevalence of early VA failure in our study was lower than that of the past reports despite worse patient condition.

In the previous reports, the diameter of the artery or vein is associated with the patency and maturation of VA [3-6]. In this study, the diameters of the artery and vein were not assessed; however, our hospital creates AVF when the diameters of the artery and vein are more than 1.5 to $2 \mathrm{~mm}$ with mapping by ultrasonography $[7,8]$. As this study is from a single center, there seems to be little variability of the diameter of the artery and vein used for VA creation.

Previous reports suggested that the level of CRP, the presence of diabetes mellitus (DM), and hypertension (HT) are associated with early VA failure [1, 2, 9]. However, our results did not show significant association between early VA failure and DM or HT. As many elderly patients included in our study were already diagnosed with advanced atherosclerotic diseases, the effects of DM and HT were likely diminished. There have been no reports assessing appropriate timing of VA creation during acute-phase illness. Our study is considered to be extremely clinically useful and meaningful.
Table 5 Characteristics of patient-created AVF with and without early VA failure

\begin{tabular}{|c|c|c|c|}
\hline Parameter & $\begin{array}{l}\text { Without failure } \\
(n=296)\end{array}$ & $\begin{array}{l}\text { With failure } \\
(n=35)\end{array}$ & $P$ value \\
\hline Age (years) & $66.4 \pm 15.0$ & $67.8 \pm 17.1$ & 0.5903 \\
\hline Male (\%) & 68.2 & 57.1 & 0.1864 \\
\hline Diabetes (\%) & 45.6 & 48.6 & 0.7393 \\
\hline Hypertension (\%) & 70.6 & 71.4 & 0.9197 \\
\hline Atrial fibrillation (\%) & 8.5 & 11.4 & 0.5551 \\
\hline \multicolumn{4}{|l|}{ Primary cause of admission } \\
\hline Exacerbation of CRF (\%) & 65.9 & 62.9 & 0.7221 \\
\hline Heart disease (\%) & 13.9 & 14.3 & 0.9440 \\
\hline Heart failure (\%) & 10.5 & 14.3 & 0.4933 \\
\hline Coronary artery disease (\%) & 2.0 & 0.0 & 0.3953 \\
\hline Infectious disease (\%) & 5.4 & 8.6 & 0.4464 \\
\hline Malignancy (\%) & 4.1 & 5.7 & 0.6444 \\
\hline Cephalopathy (\%) & 3.0 & 2.9 & 0.9522 \\
\hline Cerebral infarction (\%) & 0.7 & 2.9 & 0.1978 \\
\hline Intracranial hemorrhage (\%) & 1.0 & 0.0 & 0.5496 \\
\hline Peripheral artery disease (\%) & 0.7 & 2.9 & 0.1978 \\
\hline Aortic disease (\%) & 1.4 & 0.0 & 0.4890 \\
\hline Others (\%) & 5.7 & 2.9 & 0.4764 \\
\hline Warfarin (\%) & 10.5 & 11.4 & 0.8620 \\
\hline Antiplatelet agent (\%) & 27.0 & 22.9 & 0.5975 \\
\hline Statin (\%) & 32.4 & 22.9 & 0.2485 \\
\hline ACEi or ARB (\%) & 49.0 & 45.7 & 0.7142 \\
\hline Beta blocker (\%) & 33.1 & 25.7 & 0.3765 \\
\hline CCB (\%) & 63.5 & 71.4 & 0.3552 \\
\hline LVEF (\%) & $56.0 \pm 12.5$ & $56.8 \pm 13.3$ & 0.7316 \\
\hline $\mathrm{SBP}(\mathrm{mmHg})$ & $138.9 \pm 24.7$ & $132.6 \pm 23.4$ & 0.1568 \\
\hline $\mathrm{DBP}(\mathrm{mmHg})$ & $75.5 \pm 16.6$ & $71.1 \pm 14.5$ & 0.1309 \\
\hline WBC $\left(10^{3} / \mu \mathrm{L}\right)$ & $7.2 \pm 3.2$ & $8.4 \pm 3.6$ & $0.0376^{*}$ \\
\hline $\mathrm{Hb}(\mathrm{g} / \mathrm{dL})$ & $9.7 \pm 1.8$ & $9.7 \pm 1.7$ & 0.8780 \\
\hline $\operatorname{PLT}\left(10^{4} / \mu \mathrm{L}\right)$ & $19.2 \pm 8.1$ & $21.2 \pm 8.9$ & 0.1666 \\
\hline $\mathrm{TP}(\mathrm{g} / \mathrm{dL})$ & $6.1 \pm 0.9$ & $5.8 \pm 0.9$ & 0.0540 \\
\hline ALB (g/dL) & $3.1 \pm 0.6$ & $2.6 \pm 0.7$ & $0.0006^{* *}$ \\
\hline BUN (mg/dL) & $70.1 \pm 29.2$ & $60.2 \pm 27.8$ & 0.0578 \\
\hline $\mathrm{Cr}(\mathrm{mg} / \mathrm{dL})$ & $7.6 \pm 3.0$ & $6.9 \pm 2.6$ & 0.1933 \\
\hline $\mathrm{eGFR}\left(\mathrm{mL} / \mathrm{min} / 1.7 \mathrm{~m}^{2}\right)$ & $7.1 \pm 3.8$ & $7.4 \pm 3.5$ & 0.6445 \\
\hline AST (IU/L) & $22.6 \pm 20.3$ & $21.9 \pm 12.0$ & 0.8438 \\
\hline ALT (IU/L) & $18.6 \pm 20.9$ & $15.6 \pm 15.9$ & 0.4238 \\
\hline CRP (mg/dL) & $2.3 \pm 3.4$ & $2.7 \pm 4.6$ & 0.5259 \\
\hline APTT & $30.7 \pm 14.2$ & $28.7 \pm 4.7$ & 0.4961 \\
\hline PT-INR & $1.17 \pm 0.42$ & $1.14 \pm 0.25$ & 0.6554 \\
\hline
\end{tabular}

$V A$ vascular access, $C R F$ chronic renal failure, $A C E i$ angiotensin-converting enzyme inhibitor, $A R B$ angiotensin receptor blocker, $C C B$ calcium channel blocker, LVEF left ventricular ejection fraction, $S B P$ systolic blood pressure, $D B P$ diastolic blood pressure, $W B C$ white blood cell, $H b$ hemoglobin, $P L T$ platelet, $T P$ total protein, $A L B$ albumin, $B U N$ blood urea nitrogen, $C r$ creatinine, eGFR estimated glomerular filtration rate, $A S T$ aspartate aminotransferase, $A L T$ Alanine transaminase, CRP C-reactive protein, APTT activated partial thromboplastin time, PT-INR international normalized ratio of prothrombin time ${ }^{*} P<0.05 ;{ }^{* *} P<0.01$ 
Table 6 Odds ratio for early VA (AVF) failure with evaluated parameters (non-adjusted)

\begin{tabular}{lcll}
\hline Parameter & Odds ratio & $95 \% \mathrm{Cl}$ & $P$ value \\
\hline WBC $\left(10^{3} / \mu \mathrm{L}\right)$ & 1.0950 & $1.0024-1.1961$ & $0.0441^{*}$ \\
ALB $(\mathrm{g} / \mathrm{dL})$ & 0.3849 & $0.2187-0.6772$ & $0.0009^{* *}$ \\
\hline
\end{tabular}

$V A$ vascular access, $A V F$ arteriovenous fistula, $C l$ confidence interval, $W B C$ white blood cell, $A L B$ albumin

${ }^{*} P<0.05 ;{ }^{* *} P<0.01$

Hypoalbuminemia, which results in intravascular volume reduction, is considered to be a factor in occlusion of VA. There was a previous report which described that hypoalbuminemia was a cause of VA failure [10]. However, this report did not focus on the patients' state, different from our study which focused on acute-phase patients. There is another report which described that hyperinsulinism is a cause of VA failure [11]. However, this report did not focus on the patients' status, as well. Furthermore, inflammation may induce excessive coagulation of blood. Since hypoalbuminemia progresses during times of inflammation, it may also be considered an indication of inflammation. When hypoalbuminemia and/or inflammation are present, unphysiological blood flow, such as present in a shunt, seems likely to occlude before maturation. In that sense, adjusting the timing of VA creation to when the influence of the acute illness has faded might be effective in order to prevent early VA failure. However, when patients are complicated with dialysis catheter-related blood stream infections and require VA creation as soon as possible, a heparin infusion or supporting intravascular volume may be choices to prevent excessive coagulation.

This study has some limitations. First, this study is a single center study in Japan. Recently, the number of elderly patients in Japan initiated into dialysis therapy is increasing [12], and the vascular state of these patients is poor due to age or other complications. This result may be difficult to apply in other countries where a majority of patients initiated into dialysis therapy are younger. However, despite adverse patient conditions, our results were superior to other reports on early VA failure rate. In addition, although using a single facility is a limitation, the fact of less variation in operator competence may be a benefit.

Second, although we included acute-phase illness, we did not assess the severity of illness by using acute physiology

Table 7 Odds ratio for early VA (AVF) failure with evaluated parameters (adjusted)

\begin{tabular}{llll}
\hline Parameter & Odds ratio & $95 \% \mathrm{Cl}$ & $P$ value \\
\hline WBC $\left(10^{3} / \mu \mathrm{L}\right)$ & 1.0798 & $0.9835-1.1855$ & 0.1073 \\
ALB $(\mathrm{g} / \mathrm{dL})$ & 0.4198 & $0.2339-0.7533$ & $0.0036^{* *}$
\end{tabular}

Adjusted by age, gender, diabetes, WBC, and ALB

$V A$ vascular access, $A V F$ arteriovenous fistula, $C l$ confidence interval, $W B C$ white blood cell, $A L B$ albumin

${ }^{* *} P<0.01$ and chronic health evaluation (APACHE) II scores [13] or sequential organ failure assessment (SOFA) scores [14]. Since not all the patients were admitted to an intensive care unit, this could affect the results.

\section{Conclusions}

When performing VA creation in acute-phase illness patients, hypoalbuminemia is associated with the risk of early VA failure. We must consider a factor in the serum ALB level when deciding the timing of VA creation.

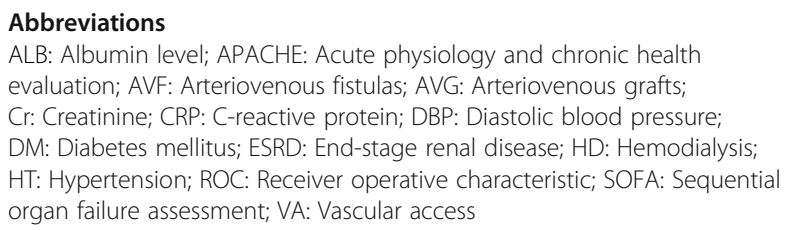

Acknowledgements

We would like to thank Editage (www.editage.jp) for the English language editing.

Funding

Not applicable.

\section{Availability of data and materials}

Please contact the author for data requests.

\section{Authors' contributions}

AT designed this study, performed the statistical analysis, and wrote this manuscript. All authors participated in the medical care for the patients in this paper. All authors read and approved the final manuscript.

\section{Competing interests}

The authors declare that they have no competing interests.

\section{Consent for publication}

Not applicable.

\section{Ethics approval}

The study was approved by the Ethical Committee of the Institutional Review Board of the Japanese Red Cross Nagoya Daini Hospital (approval number 1110) and was conducted under the Declaration of Helsinki.

Received: 21 August 2016 Accepted: 22 October 2016

Published online: 06 November 2016

\section{References}

1. Rezapour M, Khavanin Zadeh M, Sepehri MM. Implementation of predictive data mining techniques for identifying risk factors of early AVF failure in hemodialysis patients. Comput Math Methods Med. 2013;2013:830745. doi: 10.1155/2013/830745. Epub 2013 Jun 4.

2. Bahadi A, Hamzi MA, Farouki MR, Montasser D, Zajjari Y, Arache W, et al. Predictors of early vascular-access failure in patients on hemodialysis. Saudi J Kidney Dis Transpl. 2012;23(1):83-7.

3. Malovrh M. Native arteriovenous fistula: preoperative evaluation. Am J Kidney Dis. 2002;39(6):1218-25.

4. Wong V, Ward R, Taylor J, Selvakumar S, How TV, Bakran A. Factors associated with early failure of arteriovenous fistulae for haemodialysis access. Eur J Vasc Endovasc Surg. 1996;12(2):207-13.

5. Parmar J, Aslam M, Standfield N. Pre-operative radial arterial diameter predicts early failure of arteriovenous fistula (AVF) for haemodialysis. Eur J Vasc Endovasc Surg. 2007:33(1):113-5.

6. Silva Jr MB, Hobson 2nd RW, Pappas PJ, Jamil Z, Araki CT, Goldberg MC, et al. A strategy for increasing use of autogenous hemodialysis access procedures: impact of preoperative noninvasive evaluation. J Vasc Surg. 1998;27(2):302-7. 
7. Kordzadeh A, Chung J, Panayiotopoulos YP. Cephalic vein and radial artery diameter in formation of radiocephalic arteriovenous fistula: a systematic review. J Vasc Access. 2015;16(6):506-11.

8. Kukita K, Ohira S, Amano I, Naito H, Azuma N, Ikeda K, et al. 2011 update Japanese Society for Dialysis Therapy Guidelines of Vascular Access Construction and Repair for Chronic Hemodialysis. Ther Apher Dial. 2015;19 Suppl 1:1-39.

9. Khavanin Zadeh M, Mohammadipour S, Omrani Z. Correlation between CRP and early failure of arteriovenous fistula (AVF). Med J Islam Repub Iran. 2015; 29:219. eCollection 2015.

10. Zhou L, Liu H, Liu F, Wu H, Zhang L, Li Z, et al. Survival analysis and risk factors for arteriovenous fistula in 472 patients. Zhong Nan Da Xue Xue Bao Yi Xue Ban. 2015;40(8):902-6.

11. Akin D, Ozmen S, Kaya R. A novel factor for primary arteriovenous fistula failure: hyperinsulinism. Ren Fail. 2016;38(8):1206-9.

12. Masakane I, Nakai S, Ogata S, Kimata N, Hanafusa N, Hamano T, et al. An overview of regular dialysis treatment in Japan (as of 31 December 2013). Ther Apher Dial. 2015;19(6):540-74.

13. Knaus WA, Draper EA, Wagner DP, Zimmerman JE. APACHE II: a severity of disease classification system. Crit Care Med. 1985;13(10):818-29.

14. Vincent JL, Moreno R, Takala J, Willatts S, De Mendonça A, Bruining H, et al. The SOFA (Sepsis-related Organ Failure Assessment) score to describe organ dysfunction/failure. On behalf of the Working Group on Sepsis-Related Problems of the European Society of Intensive Care Medicine. Intensive Care Med. 1996;22(7):707-10

\section{Submit your next manuscript to BioMed Central and we will help you at every step:}

- We accept pre-submission inquiries

- Our selector tool helps you to find the most relevant journal

- We provide round the clock customer support

- Convenient online submission

- Thorough peer review

- Inclusion in PubMed and all major indexing services

- Maximum visibility for your research

Submit your manuscript at www.biomedcentral.com/submit

) Biomed Central 